\title{
Nuevas fuentes para el estudio de la erupción del volcán de Taal en 1754/
}

New Sources to Study the Volcanic Eruption of Taal in 1754

\author{
José Ángel del Barrio Muñoz
}

Universidad Nacional de Educación a Distancia, Madrid

El presente trabajo pretende profundizar en el estudio de las consecuencias de los desastres naturales en el pasado. En este caso, aportamos nuevas fuentes del siglo XVIII, tanto escritas como gráficas, que nos permiten evaluar mejor los acontecimientos acaecidos en la laguna de Taal en 1754, contrastándolas con otras fuentes de información reunidas hasta ahora.

PALABRAS ClaVE: Volcanes; Filipinas; Taal; Desastres naturales.

The present work intends to go in depth about the consequences of natural disasters in the past. In this case, we are providing with some new sources from the XVIII Century - either written and graphic - that allow us a better assessment of the events that took place in the Lake of Taal in 1754, making a comparison with other sources gathered so far.

KEYWORDS: Volcanoes; Philippines; Taal; Natural disasters. 


\author{
¡Pobres ciudades del lago! \\ Como Naxos, Hybla, Inessa, \\ Os reducirá a pavesa \\ Fulmíneo, terrible estrago. \\ Dejad del sueño el halago, \\ Huid sin perder instante, \\ Volad, que empieza el gigante \\ Su obra de destrucción, \\ Y es toda la isla un turbión \\ De llamas desesperante
}

El Volcán de Taal. Poema

Los medios de comunicación actuales son capaces de poner al hombre contemporáneo frente a los acontecimientos más pavorosos en un espacio de tiempo reducido. Sin abandonar su hogar será espectador de las mayores demostraciones de fuerza de la Naturaleza, contemplando sobrecogido el sufrimiento de miles de semejantes, inermes ante la furia de los elementos. Hora tras hora, conocerá el esfuerzo de las autoridades para mitigar los daños y la labor de los científicos para dilucidar las causas y descubrir más misterios del entorno físico y natural en el que vive inmerso el ser humano. De hecho, las ciencias han dado pasos de gigante en el estudio y comprensión de los desastres naturales, y puede decirse que la Historia realiza también su aportación a través del conocimiento de las catástrofes del pasado, ayudando de esta manera a su prevención futura. ${ }^{2} \mathrm{~A}$ pesar de todo, queda mucho por hacer... ${ }^{3}$

Este trabajo pretende contribuir a ello, ofreciendo fuentes hasta ahora poco o nada conocidas para profundizar en el estudio de la erupción volcánica acaecida en la Laguna de Taal o Bombón (Luzón, Filipinas) en 1754. Un cataclismo que ha llamado la atención de diferentes cronistas e historiadores, y que ha producido diversos trabajos de interés. En nuestro caso, exponemos las palabras de quienes fueron testigos oculares y vivieron los

1 Mas y Otzet, 1885, 57.

2 Un estudio contemporáneo sobre gestión de desastres naturales afirma sobre el aporte de las fuentes históricas españolas: «Disaster management during the Spanish period was an area given importance by the colonial rulers [...] The first notable step toward management taken by the Spanish rulers was to establish an accounting of disaster events as they occurred. Their accounts of calamities and disaster events between 1521 and 1898 are considered one of the bases for development of the present day early warning system for disaster management of typhoons, volcanic eruptions and earthquakes». Asian Disaster Preparedness Centre, 2001, 7. En este sentido, véase Donoso Jiménez, 2006.

3 Cada vez es mayor el interés por el estudio de la influencia de la naturaleza en la historia humana. Entre los títulos recientes está el de Parker, 2013. En España destacan Petit-Breuilh, 2004a y 2006, así como Alberola, 2009 y 2013. 
hechos, acompañadas de dibujos realizados al efecto. Unos diseños que constituyen, a su manera, el testimonio gráfico del desastre en una época carente de fotografía y medios audiovisuales. Un reflejo del asombro, del sobrecogimiento y de la fascinación de quien, sin duda, no había presenciado antes nada parecido. Y, finalmente, aportamos los datos de la Administración, cartas e informes del Superior Gobierno de Manila que, en un lenguaje más frío, informan de lo sucedido, hablan de víctimas, arrojan datos sobre refugiados o bien dan cuenta de la ayuda proporcionada.

\section{Crítica previa de algunas fuentes utilizadas}

Para la descripción de los acontecimientos de aquellos aciagos días de 1754 vamos a servirnos de dos relatos que conviene analizar de cerca. El primero de estos documentos lleva por título Relacion de lo sucedido en el Bolcan de la Provincia de Tal, y Balayan en Año 1754, y se encuentra en el Archivo Franciscano Ibero-Oriental de Madrid. ${ }^{4}$ No tiene fecha ni firma. Sin embargo, en la última hoja, en su margen inferior izquierdo, puede leerse escrito con letra distinta a la del conjunto del manuscrito: «Hecha por el Pe. Fr. Manuel Braña, Religioso Agustino, Prior de Tanauan». Algo más abajo, también con tinta y letra diferentes, reza: «Fecho año de 1754 y 1751». Creemos que estas acotaciones fueron realizadas por alguien que recibió el manuscrito posteriormente y que, sin duda, tuvo que indagar acerca de su autor y del momento de la redacción. Y en ambos casos, como vamos a ver, cometiendo algunas equivocaciones.

Primeramente, debe señalarse que este documento tiene toda la apariencia de ser un original, por el modo tan elaborado como se presenta, incluyendo además dos acuarelas sobre los sucesos de Taal. Nada propio de una mera copia. Se encuentra en un archivo distinto al de la comunidad religiosa del que sería su ejecutor, un agustino. Quizá se trate de un obsequio entre religiosos, aunque también es posible que el manuscrito llegara a la Orden de los Frailes Menores tras el expolio del Archivo agustino durante la ocupación británica de Manila en 1762, obligando a inquirir quién lo realizó y cuándo. En lo referente a la fecha, durante la narración de los hechos el autor habla brevemente, hacia el final de su escrito, de algunos sucesos acaecidos concretamente tres años después de la erupción, con lo cual la fecha de elaboración se enmarca entre 1754 y 1757, y no

4 Archivo Franciscano Ibero-Oriental (AFIO), 50/15. 
1751, como indica la acotación, lo que a nuestro ver es una mera inadvertencia o error formal del amanuense.

En cuanto al autor, según nuestras investigaciones ${ }^{5}$ no existió nunca en Filipinas ningún Manuel Braña, y sí en cambio un Miguel Braña, nombrado precisamente párroco de Tanauán, pueblo de la laguna de Taal, en 1753, cargo que ejerció hasta 1756. Sin duda otro error de forma cometido por quien añadió las notas marginales. ${ }^{6}$ ¿Quién era fray Miguel Braña? Nació en 1719 en Villamoronta (Palencia), profesando en la orden agustiniana en México en 1738. Al año siguiente llegó a Filipinas, dedicándose a aprender el tagalo (se le atribuye la elaboración de un diccionario). Fue párroco en Tondo en 1750, ministerio que ocuparía en otras ocasiones. En 1753 le nombraron ministro de Tanauan, en 1756 de Bauán y en 1765 de Batangas, lugares situados en la esfera de la laguna de Taal. Jugó un papel destacado durante la ocupación británica de Manila, ya que estuvo encargado del abastecimiento de víveres y del pago de las tropas españolas que, bajo la dirección de Simón de Anda, resistían al invasor. Desempeñó bastante bien este cometido, burlando varias veces a los soldados ingleses, quienes pusieron un gran empeño en apoderarse de su persona, aunque siempre sin éxito. El padre Braña murió en 1774 en Imus (Cavite), siendo sepultado en Manila. ${ }^{7}$

El segundo documento que vamos a utilizar se encuentra en el Archivo General de la Nación de México: Descripcion Ajustada y exacta Relacion del Bolcan de Taal, y su furiosa erupcion en el año de 1754; y sobre el título, se lee: «Año de $1755 » .{ }^{8}$ Se trata también de otro manuscrito carente de firma, sin que en este caso nos encontremos con ningún tipo de acotaciones ni notas que nos permitan dilucidar la autoría. Su soporte no es el tan común papel de arroz usado entonces en Filipinas - que es el que utiliza el escrito del padre Braña-, sino que emplea papel del que se producía en Europa. Asimismo, carece de cualquier tipo de esmero estético, dando la impresión de tratarse de una copia de otro documento original, recogiendo quizá información recibida por la Administración virreinal de Nueva España. ${ }^{9}$

5 Agradezco mucho la información recibida mediante la consulta que realicé al padre Blas Sierra, gran filipinista y buen conocedor de la historia de su Orden.

6 Quizá porque hubiera encontrado abreviado el nombre de Miguel y lo confundiera con el de Manuel.

7 Pérez, 1901, 277-278. Aragonés, 1864, 163.

8 Archivo General de la Nación de México (AGN), Instituciones Coloniales, Gobierno Virreinal, Filipinas (048), contenedor 02, volumen 4, exp. 1, 1-22.

9 En México hay otros escritos relativos a los sucesos de Taal en 1754. Así, Relación de lo sucedido con el volcán de la laguna de Bong-Bong, Provincia de Taal y Balayang, Biblioteca Nacional de México, Fondo Reservado, Ms. 488 (22-12-1754, copia), 44-56v. 
Lo que llama la atención es la gran similitud que existe entre el escrito del padre Braña y el anónimo de México. La estructura de ambos documentos es análoga: presentación de la provincia de Balayán, entorno del volcán, y exposición de los acontecimientos, aunque el fraile agustino es más prolijo y finaliza su narración de manera menos abrupta. En cuanto a la redacción, en ocasiones hay párrafos prácticamente idénticos, donde se usan incluso las mismas frases y ejemplos. Todo ello nos lleva a concluir que o bien Miguel Braña conocía el anónimo de México o, lo que nos parece más probable, se trata de su autor: en un primer momento compuso aquel documento (que fue enviado a México) y posteriormente lo perfeccionó, añadiendo detalles e incluyendo dos acuarelas. Así se explica que la acotación final del escrito que se encuentra en el archivo franciscano diga que se redactó a lo largo de tres años.

En el presente trabajo vamos a llevar a cabo la exposición de los acontecimientos de 1754 sobre la base del manuscrito de Miguel Braña, acudiendo al anónimo cuando éste complete los sucesos. Al mismo tiempo, iremos señalando algunos ejemplos que demuestren las similitudes que existen entre ambos documentos, y que creemos dejan claro que son obra del mismo personaje.

\section{El volcán de Taal}

El fenómeno volcánico es de enorme trascendencia en Filipinas hasta el día de hoy. Las manifestaciones eruptivas empezaron a cobrar especial importancia en el archipiélago durante el periodo Terciario, con una actividad relevante en el Cuaternario, que influiría en el desarrollo del relieve y en diversos cambios tectónicos. Dentro de esta dinámica, el volcán de Taal, junto con otros centros como los de Mayón y Pinatubo, en Luzón, el de Canlaón, en Negros, y el de Apo, en Mindanao, constituye uno de los principales focos de vulcanismo explosivo de las islas Filipinas. ${ }^{10}$

10 Véase Centeno, 1885, 2-24; Hargrove, 1991, 1-20 y Antón Burgos, 2000, 17-46. Asimismo: http://www.volcano.si.edu/world/volcano.cfm?vnum=0703-07\%3D, perteneciente al Smithsonian Institut, con datos sobre geología y vulcanismo; http://www.iml.rwth-aachen.de/ Petrographie/taal-mas/ta-maso.htm, que resume el trabajo del sacerdote Miguel Saderra sobre la brutal erupción de 1911; y http://www.phivolcs.dost.gov.ph/html/update_VMEPD/Volcano/VolcanoList/ taal.htm, del Philippine Institute of Volcanology and Seismology. (Últimas consultas, 29 de julio de 2014). 


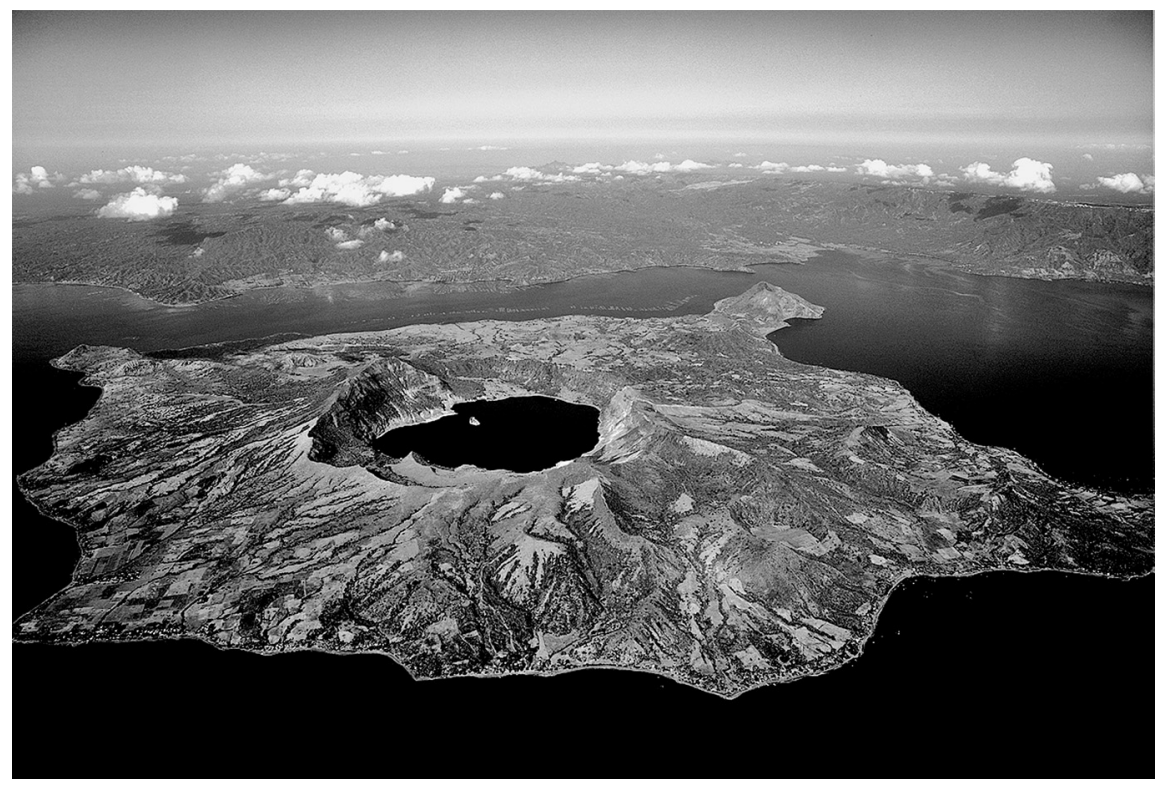

Figura 1. Vista aérea del volcán de Taal. El norte corresponde a la parte derecha.

(Foto: The Coffe. Mike González).

La laguna de Taal, también llamada en lengua local Bongbong, es una caldera de aguas ligeramente saladas, con un perímetro aproximado de 120 kilómetros, formada a partir de una erupción volcánica. Desde sus márgenes el terreno se va elevando, con dos puntos culminantes en el relieve, los picos Macolot y Sungay, ninguno de los cuales alcanza los 1000 metros. No existen ríos realmente importantes que desagüen en el lago. La profundidad de la laguna es reseñable, dado su tamaño, oscilando entre los 90 y los 160 metros. En el centro se sitúa una isla, que cubre unos $23 \mathrm{~km}^{2}$, y en la misma se encuentra el volcán (polo, en lengua nativa), al que los españoles denominarían de Taal, Bongbong o Bombón. No obstante, sería más propio hablar de volcanes, toda vez que la actividad geológica ha hecho que surjan diversos conos y cráteres menores en diferentes puntos de esta isla. Con todo, existe un cráter principal de casi 2 kilómetros de diámetro, en cuyo fondo hay un lago fruto de la erupción acaecida en 1911.

La primera alusión histórica al volcán de Taal la realiza el agustino Gaspar de San Agustín, al referirse a la fundación de la villa de Taal junto al lago allá por 1572. En 1591 otro agustino, fray Bartolomé de Alcántara, 
efectuó un exorcismo con motivo de la actividad del volcán, que comenzó a expeler humo. En la primera mitad del siglo XVII se menciona el enclave en diversas ocasiones, pues parece ser que hubo ligeras erupciones. Pero, en general, hasta 1707, año en que se consigna la primera erupción bien detallada, la actividad del volcán no parece haber sido realmente amenazadora. A lo largo de la primera mitad del siglo XVIII poseemos noticias de erupciones los años 1705, 1707, 1716, 1729, 1731 y 1749, hasta que se produjo la de 1754, la más virulenta de cuantas hasta entonces se habían registrado.

La laguna de Taal captó también la atención de los españoles por motivos de carácter estratégico. A comienzos del siglo XVII había quedado patente que Manila adolecía de un grave problema al existir apenas una entrada por la boca de la bahía, pues la ciudad podía ser fácilmente bloqueada por cualquier enemigo que tomase u obstruyese este acceso. Para remediarlo, el procurador Fernando de los Ríos Coronel propuso a la Corte la apertura de dos salidas alternativas utilizando sendos ríos: uno, el de Tarlac, hacia Zambales, y el otro en dirección a la laguna de Taal, que poseía comunicación con el mar. En 1622 se ordenó al gobernador Alonso Fajardo la ejecución del plan, pero no se hizo nada. Así que en 1633 Juan Grau y Monfalcón envió un nuevo memorial a España solicitando que se forzase a actuar al Gobierno manilense. Pero el gobernador Sebastián Hurtado de Corcuera tampoco se mostró favorable a la idea, con lo que la obra, finalmente, jamás se llevó a cabo. ${ }^{11}$ Observando la figura número 2 podremos darnos cuenta del alcance que tenía el proyecto de Ríos Coronel. Se trata de un mapa posterior, elaborado en $1741,{ }^{12}$ pero se aprecia con claridad un canal que se inicia cerca de donde se situaba entonces el pueblo de Taal, comunicando la laguna con el mar a la altura del antiguo santuario de Caysasay, en la bahía de Balayán. Nunca se ejecutó aquel programa de ingeniería, aunque quizá hubiera sido un esfuerzo en balde, ya que, a raíz de la erupción de 1754 , este canal iba a quedar cegado. ${ }^{13}$

11 Archivo General de Indias (AGI), Filipinas, 340, libro 3, 269v-270v, Real Cédula al gobernador de Filipinas sobre proyecto de apertura de dos ríos, Madrid, 29 de mayo de 1620. AGI, Filipinas, 27, n. 168, Petición del cabildo secular de Manila sobre abrir dos ríos en Manila, Manila, 15 de julio de 1633 (probable). AGI, Filipinas, 330, libro 4, 109r-v.

12 AGN, Instituciones Coloniales, Colecciones, Mapas, Planos e Ilustraciones (280).

13 En este sentido, son interesantes los datos que proporciona Hargrove, 1991, 118-120 y 127-129. Materia volcánica mezclada con lluvia de barro, junto con la acción de tifones, debieron producir el cierre del canal. Un hecho que, al parecer, ha provocado también cambios en la composición del agua del lago. 


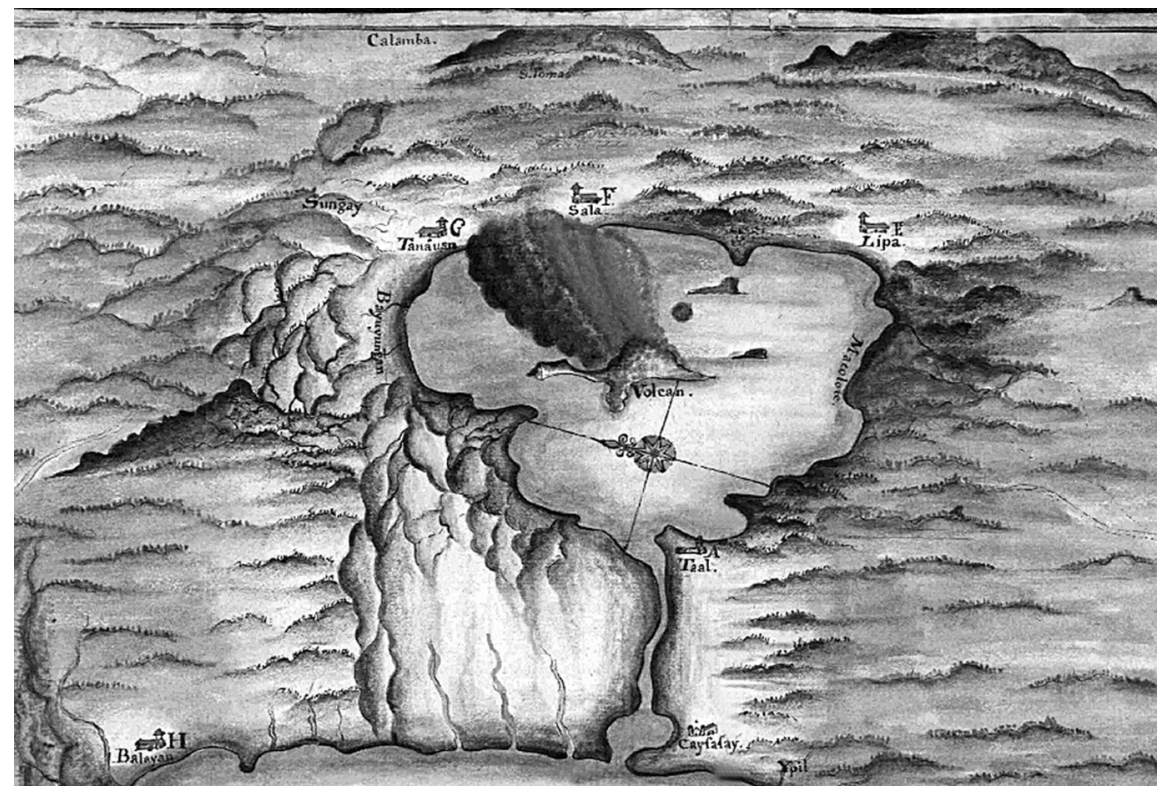

Figura 2. Mapa de la laguna y volcán de Taal dibujado en 1741 (Archivo General de la Nación, Mapas, Planos e Ilustraciones, 280). Puede distinguirse claramente la existencia de una corriente de agua a modo de canal entre Taal y Caysasay.

\section{Qui est vir sapiens qui intelligat? La erupción de 1749 como preludio}

Taal había rugido en 1731 y volvería a hacerlo con virulencia en 1749, como si fuera una advertencia de lo que habría de venir. Hacia las 3 de la mañana del día 11 de agosto el volcán inició una intensa actividad, eyectando lava y tefra, junto con una gran columna de humo, mientras el suelo de las márgenes del lago temblaba y se agrietaba. Una violenta erupción que se ha calificado como freatomagmática. ${ }^{14} \mathrm{El}$ jesuita Pedro Murillo Velarde, contemporáneo de estos acontecimientos, narra así el suceso: ${ }^{15}$

A 11 de agosto de 1749 reventó el volcán de esta Laguna, brotando fuego por las dos isletas, y por otras cuatro bocas por medio del agua. Calentola el fuego, de manera, que hervía, y mató todo el pescado, que arrojó muerto en gran cantidad a las

14 Hargrove, 1991, 27 y 146. Véase también la información que aparece en la página web del Philipine Institute of Volcanology and Seismology (PHIVOLCS).

15 Murillo, 1752, 58-59. 
playas. Llovió ceniza tres días, tan espesa, que era menester encender luces aún a mediodía. Tembló la tierra con indecible violencia, tres, o cuatro veces, y con más suavidad más de cien veces, y continuó temblando más de un año. Se abrió la tierra con profundísimas, y grandes aperturas por varias partes. Yo estaba en Antípolo, distante como 20 leguas, y fue tan violento el golpe que la Torre arrojó más de seis brazas las tejas, y se caían los libros de los estantes; y vinieron huyendo al pueblo muchos venados, y otros animales del monte, que con berridos, acompañados de los perros, causaban espanto. Se siguieron grandes tempestades de truenos por muchos días, y algunas tan horribles, que caían los rayos, como granizo. Después hubo grandísimas lluvias.

Contamos con una fuente inestimable para el estudio de esta erupción: un diseño elaborado por un testigo presencial que dejó plasmado cuanto contempló (véase figura 3). Se trata de una acuarela que está en el Archivo Franciscano, ${ }^{16}$ y en ella el artista ha materializado su observación de los sucesos desde el pueblo de Taal, trazando dos cortes de la laguna entre los montes Sungay y Macolot, casi en dirección norte-sur. Los dibujos están fechados el 13 de agosto, apenas dos días después de que se iniciara la actividad volcánica, e incluyen una breve descripción de lo sucedido. En cuanto al autor, no queda claro. La única firma existente en el documento es la de un tal Manuel Magno de Valenzuela, inserta al pie de una nota añadida meses después, en julio de 1750. Quizá sea Valenzuela el autor, o tal vez sólo quien adjuntó el comentario, a raíz de las noticias recibidas sobre la acción del volcán.

En el primer dibujo apreciamos la actividad volcánica desde las 7 de la mañana hasta el inicio de la tarde: el volcán principal (Polo Grande), genera una columna convectiva entre emisiones magmáticas, mientras que un proceso análogo se aprecia en el Polo Nuevo y en otros dos puntos más del interior de la laguna. Esto concuerda con la descripción que hace Murillo Velarde, cuando afirma que «reventó el volcán de esta Laguna, brotando fuego por las dos isletas, y por otras cuatro bocas por medio del agua». En cuanto a los dos grupos de columnas de humo que se advierten en el diseño, cabría preguntarse si es vapor generado por las altas temperaturas (Murillo refiere también que la laguna «hervía»), o producto de la propia erupción freática. Aunque quizá reflejen algún tipo de flujos piroclásticos, formados por gases volcánicos y fragmentos sólidos calientes que se están desplazando a nivel del suelo. El segundo dibujo muestra la actividad volcánica desde el mediodía hasta las 5 de la tarde: ha quedado restringida al volcán

16 AFIO, 50/21, Carpeta núm. 6 de Mapas y dibujos. 


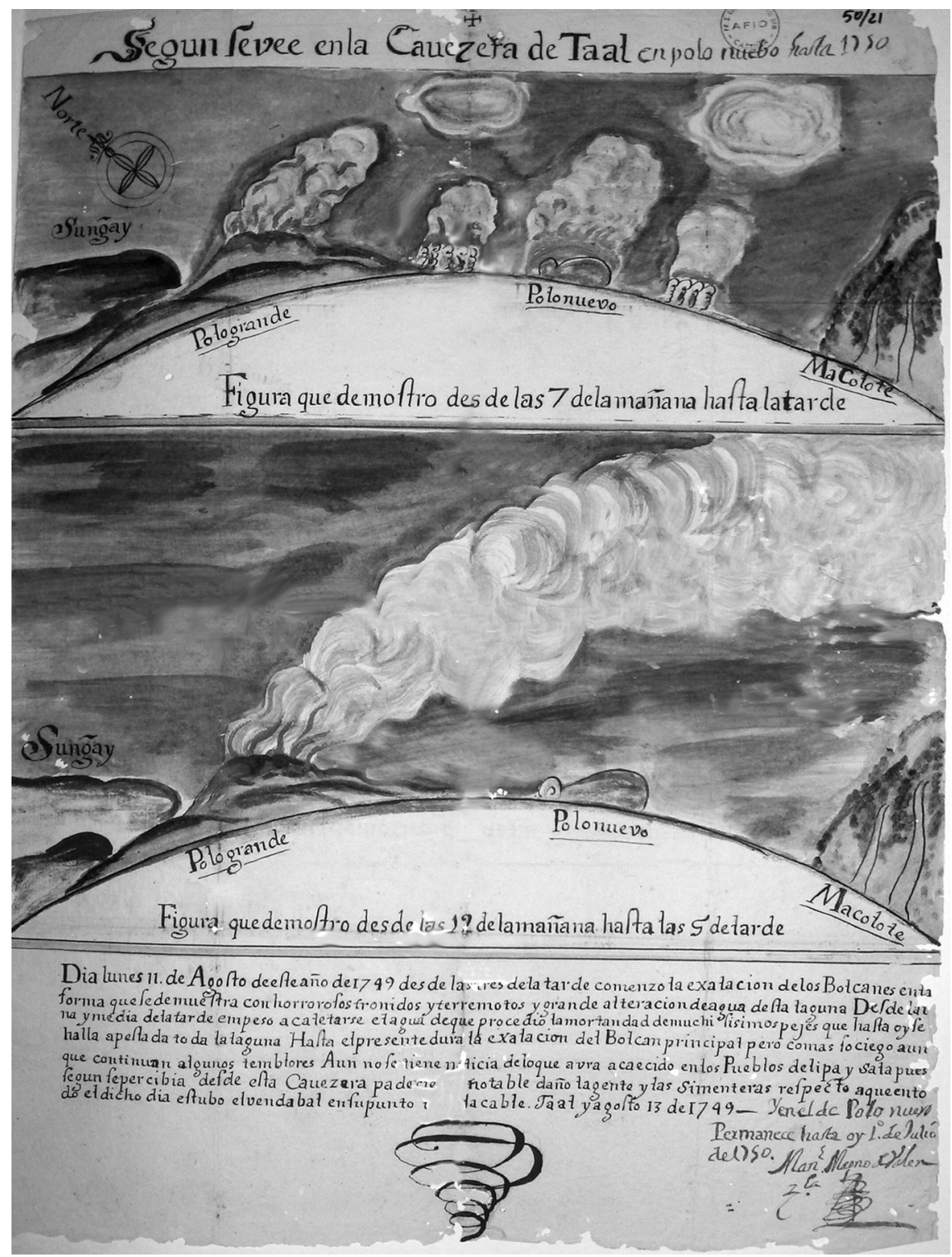

Figura 3. Dibujos representando la erupción volcánica acaecida en la laguna de Taal en 1749 (Archivo Franciscano Ibero-Oriental). 
principal, que sigue emitiendo lava y piroclastos, junto a una gran columna eruptiva. Bajo los diseños, se lee la siguiente explicación:

Día lunes 11 de Agosto de este año de 1749, desde las tres de la tarde [sic] comenzó la exhalación de los volcanes en la forma que se demuestra con horrorosos tronidos y terremotos y grande alteración de agua de esta laguna. Desde la una y media de la tarde empezó a calentarse el agua, de que procedió la mortandad de muchísimos peces, que hasta hoy se halla apestada toda la laguna. Hasta el presente dura la exhalación del volcán principal pero con más sosiego, aunque continúan algunos temblores. Aún no se tiene noticia de lo que habrá acaecido en los pueblos de Lipa y Sala, pues según se percibía desde esta Cabecera, pade[cieron] notable daño la gente y las sementeras, respecto a que en todo el dicho día estuvo el vendaval en su punto (ilegible)...acable. Taal y agosto 13 de 1749 .

Tiempo después se añadiría un breve comentario: «Y en el de Polo Nuevo permanece hasta hoy, $1^{\circ}$ de julio de 1750 ». Sí, la actividad del volcán en Taal remitió, pero no llegó a extinguirse. De hecho, se siguieron registrando signos de la misma hasta 1753 , como si fueran un preludio de la catástrofe que se avecinaba.

\section{Signum laboris, desolationis et devastationis: la gran erupción del volcán de Taal de 1754}

Dice así el agustino Miguel Braña en la primera página de su manuscrito:

El que todo lo dispuso en número, peso y medida providenció en esta Provincia de Taal una Laguna, y en esta Laguna varias isletas, y porque hay en ella una mayor que todas, se llamó por antonomasia la Isla; y por cuanto en la lengua del País la Isla se llama Polo, un volcán que hay en esta Isla grande se levantó con el nombre de Polo, por no haber término o dicción en la lengua del País que quiera decir o significar volcán, no obstante que hay tantos volcanes en esta tierra. (f. 1r)

Este volcán iba a ser el protagonista de los luctuosos días que viviría la región de Taal a partir de mayo de 1754 . Una zona hasta entonces exuberante de vida, a tenor de los documentos. Tanto el escrito de Braña como el anónimo mexicano comienzan alabando las excelencias de la «provincia de Taal» ${ }^{17}$ —en realidad de Balayán—, siendo el religioso agustino algo más

17 Vamos a distinguir entre el manuscrito atribuido a Braña del que no lleva firma alguna —al que denominaremos anónimo mexicano - a efectos meramente prácticos, aunque desde nuestro punto de vista ambos escritos son obra del mismo autor, el fraile agustino Miguel Braña. 
prolijo en su descripción, calificándola como una de las mejores regiones de Luzón, muy rica en agricultura, con mucho ganado y pescado: «Era, en fin, una Provincia de quien se podría decir no necesitaba de otra» (f. 1v). Ambos documentos reseñan los pueblos que comprendía y su número de tributos, proporcionando las mismas cifras y casi que idénticos comentarios. Según Braña, la provincia de Balayán abarcaba ocho poblaciones: Balayán, pueblo riquísimo por sus cosechas, con 1.500 tributos y diversas visitas; Taal, la cabecera, con 1.300 tributos, producía tejidos y alimentos; Bauán, de 1.200 tributos, destacaba tanto por la fertilidad de sus tierras como por la laboriosidad de sus moradores; Batangas, con 1.500 tributos, sobresalía por la gran abundancia de grano y ganado: «Ese sólo es el que se ha escapado de la infernal furia del volcán, aunque se quejan de la mala cosecha, señal que algo les ha tocado» ${ }^{18}$ Luego estaban Rosario (400 tributos), Lipa (500 tributos), Sala (150 tributos) y por último Tanauán, (250 tributos). Desde aquí hacia el oeste, bordeando la laguna, se llegaba al sitio de Bayuyungán.

Braña prosigue su relato describiendo los montes que rodean la mayor parte de la laguna, señalando los más importantes y proporcionando algunas características notables, como la riqueza de sus maderas. Se detiene en el monte Macolot, la principal altura del lago, haciendo referencia a la gran cueva que penetra en el mismo:

Este monte Macolot tiene una grande cueva por debajo, en medio de él parece entra un gran río por debajo de dicho monte; es dicho común de los naturales que tiene esta Laguna comunicación con la mar, por debajo de este monte. Lo cierto es que pasando por la falda a caballo suena a hueco (f. 2 r).

Aparte, en las montañas se había encontrado oro y, además, el carbunclo, «piedra tan preciosa que sólo es alhaja de Reyes y Monarcas» (f. 2v). El carbunclo era un nombre que se daba al rubí, y según nos indica el religioso agustino esta piedra, denominada sula en lengua indígena, se encontraba «en la cabeza de una grandísima culebra, no se sabe si es la que llaman sava». ${ }^{19}$

18 Al hablar de este pueblo, el documento de México afirma que es el único que «ha escapado de los rigores del volcán, aunque le debilitó algo la cosecha» (f. 3r). Se aprecia otra semejanza de los comentarios, corroborando nuestra teoría de que se trata de un mismo autor en diferentes momentos.

19 El anónimo mexicano, al hablar del monte Macolot, indica que «hay una gran cueva por donde parece entra un gran río, y según opinión común de los naturales tiene comunicación con el mar esta Laguna, desaguando en ella muchos ríos, hasta dieciocho (aunque sólo ocho son de caudal considerable), que descendiendo de los montes la forman y enriquecen. Hallándose en estos montes minerales de oro y aun el carbunclo, piedra preciosísima, que sobre lo pingüe de la tierra hacen rica (como se dijo) a esta Provincia» (f. 4r). 
En fin, una rica provincia que vivía con una espada de Damocles cernida continuamente sobre su cabeza, el volcán de Taal. Un volcán que, a lo largo de la primera mitad del siglo XVIII, había dado numerosas muestras de actividad, de las que tanto Braña como el anónimo de México se hacen eco, proporcionando unas breves pinceladas..$^{20}$ Así, en 1705 la acción del volcán acarreó episodios de sismicidad durante tres semanas seguidas e incluso produjo hundimientos de terrenos, destruyéndose lugares como Sirang Lupa y Bayuyungán, ${ }^{21}$ que quedaría estéril por un periodo de veinte años. Hubo nuevas erupciones en 1716, esta vez sin daños significativos, aunque la laguna aumentó su nivel considerablemente. En 1731 se vivieron tres días de actividad volcánica, sin registrarse víctimas, surgiendo en esta ocasión la Isla Nueva (o Polo Nuevo), entre el volcán principal y el monte Macolot. Se hace una referencia especial a la erupción de 1749, que ambos manuscritos señalan erróneamente acaecida el 12 de agosto — sin duda por tratarse del mismo autor-, resaltando su virulencia. Corroborando datos que ya conocemos, Braña detalla que hubo corrimientos, fracturas y hundimientos de terrenos, registrándose graves destrozos y víctimas en Sirang Lupa, lugar azotado por el volcán cuarenta años antes:

Se hundieron varias casas con sus habitadores, de suerte que era necesaria escalera no para subir, sino para bajar; y de aquí se puede inferir, o el mucho amor que tienen al lugar o en donde nacieron estos indios, o adonde tienen algún provecho; o su insensibilidad, pues viendo que aun se sepultaban vivos, y que podían huir de tan manifiesto riesgo, apenas había quien quisiese desamparar su habitación o chozuela... (f. 3v).22

Tal era el volcán de Taal, al que, en un arranque de erudición, el fraile agustino compara con el del monte Hecla, en Islandia. Una verdadera boca del infierno debido al fuego y a los bramidos que producía. De hecho, en diversas ocasiones se habían celebrado misas en lo alto y exorcismos para intentar aplacar su furia. ${ }^{23}$

20 Se citan las mismas erupciones y se alude a comentarios análogos.

21 Al oeste del lago. Hoy día es uno de los barrios que conforman el municipio de Laurel (Batangas).

22 La Descripción Ajustada anónima de México, al referir esta actitud de los habitantes de Sirang Lupa dice también que se hundieron varias casas con sus moradores, «los que (o por el amor del indio al sitio donde nace o donde encuentra algún provecho, o por su innata insensibilidad), aun viéndose sepultar vivos, no dejaron sus miserables chozas» (f. 5v).

23 El exorcismo de los volcanes era entonces una práctica corriente en todo el mundo hispánico. La primera vez que se llevó a cabo en Taal fue en 1591. En la América española, parece ser que la primera referencia a un exorcismo para aplacar la furia volcánica se data en 1582 en Quito, cuando se hizo repicar las campanas con motivo de una fuerte erupción del Pichincha. Sobre este tema véase PetitBreuilh, 2002. 
Mas lo peor aún estaba por llegar. Braña prosigue su crónica señalando que «desde que llegué a este Ministerio, que fue el día 20 de mayo de 53, empecé a notar los movimientos del Polo; por entonces sólo se veía humo; luego que llegaron las primeras aguas noté que era más que en otras ocasiones el humo...» (f. 5 r) ${ }^{24}$ El religioso se percató además de que se oían más «bramidos» (denominados ogong en la lengua del lugar), pero cuando quiso averiguar el motivo, los nativos le dijeron que era algo habitual, un fenómeno que sucedía en época de aguas, tanto cuando había más lluvia de lo usual como cuando ésta iba a cesar. ${ }^{25}$

Así transcurrió el resto del año 1753, hasta comienzos de mayo de 1754, cuando el volcán empezó a expulsar más vapor, lava y piroclastos que hasta entonces. Este incremento de la actividad alcanzó su punto culminante el día 2 de junio, que fue cuando, según Braña, «comenzaron los estragos» (f. 5v). Hasta entonces llevaban casi un mes viendo las emisiones de lava y se encontraban acostumbrados al fenómeno. Sin embargo, el aumento de actividad se hizo patente a través de estampidos y de verdaderos rugidos del volcán, «que parecía que cada uno de ellos derribaba el monte», lo que empezaría a preocupar vivamente a los habitantes de la zona. La situación se agravó a medida que cayó la noche. Como narra la crónica anónima mexicana,

...crecieron los estampidos, y truenos, de modo que parece se veían los montes abajo; el fuego llegaba a las nubes, y se extendió por todo el monte tanto que ardía casi toda la Isla, y a todos ponía en singular temor y peligro [...] Arrojaba el mismo tiempo multitud de piedras, y habiéndose levantado un poco de viento Este, como a media noche se disipó el humo, y se vio el fuego por diez leguas en contorno (f. $7 \mathrm{v}$ ).

Era la noche de la Pascua del Espíritu Santo, y el miedo se había vuelto tan intenso que, en Tanauán, Braña decidió juntar a todos los vecinos en la iglesia para llevar a cabo una serie de procesiones y actos piadosos, pensado

24 Este dato de la fecha es relevante. Como se ha señalado, fray Miguel Braña había llegado como párroco a Tanauán en 1753, con lo que esta indicación por parte del propio autor del manuscrito corrobora nuestra idea de que fue él, y no ningún posible Manuel Braña, quien redactó el texto. Por su parte, el anónimo mexicano dice: «Desde 20 de mayo del año de mil setecientos cincuenta y tres se empezaron a notar movimientos del volcán luego que llegaron las primeras aguas, con mucho fuego y bramidos...» (f. 7r). Que ponga como punto de partida de la actividad volcánica el mismo día que Braña inició su labor como párroco es demasiada coincidencia, salvo que se trate del mismo autor.

25 Cabe decir que ninguno de los dos manuscritos refiere que los naturales filipinos tuvieran ideas animistas ni creencias religiosas vinculadas al volcán como sucediera entre algunas comunidades indígenas americanas con las pacarinas (Petit-Breuilh, 2006, 21-26). Si lo hubo, ya debía haber desaparecido o, sencillamente, era algo que no se comentaba con los misioneros. 
que les podía haber llegado su última hora. A continuación, y ya durante la madrugada del siguiente día, se evacuó el pueblo. Aquella noche se perdió el sitio de Bayuyungán, el más delicioso de cuantos tenía el pueblo de Tanauán, un lugar muy productivo desde el punto de vista agrícola. Recibió una verdadera lluvia de roca, lodo y arena, «y si no fuera porque llovió verdadera agua, se hubieran abrasado los del sitio» (f. 6r). A lo largo de los siguientes días el volcán mantuvo una tónica similar, aunque con menos intensidad, recrudeciéndose la actividad efusiva de manera preocupante los días 23 y 24 de junio, a tal punto que, según confiesa Braña, hubiera clausurado la misa de San Juan «porque estaba la Iglesia en un continuo movimiento y cada tiro del volcán parecía un temblor no pequeño» (f. 6v). Sin embargo, al final retornó una cierta calma, y en esas circunstancias el agustino decidió armarse de valor, embarcó en Sala y se dirigió a Taal para inspeccionar el volcán, regresando a Tanauán bordeando la costa.

Durante su viaje, Braña observó que la elevación del volcán había sufrido una tremenda erosión en su lado sur. Estando realizando estas tareas de inspección, el 26 de junio se intensificaron de nuevo las explosiones, aumentando la columna de gas y tefra, que acabaría precipitándose sobre diversos puntos de la zona este del lago. Fue en esta ocasión que se destruyó por primera vez el pueblo de Sala, el barrio de Balili, el de Bayabas y algunos barrios del pueblo de Lipa. La actividad volcánica aquella noche fue peor que la de la Pascua del Espíritu Santo, en opinión del religioso. Al día siguiente el volcán moderó un tanto su actividad, prolongándose dicha situación desde el 27 de junio hasta el 11 de julio. Este último día, hacia las 3 de la tarde aproximadamente,

...dio tan fatal estampido, tan terribles truenos el Polo, que pensamos había venido todo el monte abajo; fueron tales las montañas de humo que echó que menos de medio cuarto de hora no se veía cosa alguna en toda la banda del Este más que humo, y en medio de la boca del volcán fuego, de suerte que en el pueblo de Lipa, a aquella misma hora les fue preciso encender candela (f. 6v). ${ }^{26}$

Aquel día quedaron destruidas la mayoría de las huertas de los pueblos de Lipa y de Sala, y nuevamente el barrio de Balili. La festividad de Santiago Apóstol el volcán hizo una nueva demostración de su potencia, «que parecía

26 Sobre este suceso el anónimo mexicano dice que fue «tal estampido que se pensó se había venido abajo todo el monte; y con las nubes de humo en toda la banda del este, en el Pueblo de Lipa, encendieron candela para manejarse a aquella hora». La descripción de esos acontecimientos puede verse en $8 \mathrm{r}-\mathrm{v}$. 
celebraba con muchas salvas reales la festividad de tan gran Santo y Patrón» (f. 7r). Llegados a este punto, tanto el relato de Braña como la Descripción Ajustada de México comentan diversos signos de carácter prodigioso que se habían notado en la naturaleza, en un intento por encontrar premoniciones, presagios y explicaciones a la espantosa realidad que vivían.

Tras los sucesos del 25 de julio volvieron unos días de actividad menos enérgica. Pero el 13 de agosto la situación se recrudeció, alcanzando su clímax el día 19, en que se registró una fuerte erupción por la noche, una de las más terribles padecidas hasta ese momento, «que parecía quería consumir todo este hemisferio» (f. 8r). Afortunadamente el ímpetu del volcán volvió a remitir un tanto, aunque sin cesar las emanaciones de lava y gases. El día 17 de septiembre la actividad volvió a ser furiosa, llegando a su auge el día 25, en que no paró de expulsar lava y piroclastos, generando destrozos en la mayor parte de los pueblos de la laguna, e incluso en zonas alejadas. Como afirma el anónimo mexicano: «Vomitó tanto fuego que desde el pueblo de San Pablo, que está más de ocho leguas distante del volcán, se veía el fuego, que parecía llegar hasta las nubes» (f. 9v). El 6 de octubre se produjo otra jornada de intensísimo vulcanismo, a tal punto que Tanauán volvió a ser evacuado.

Sobrevino luego un periodo de poca actividad y relativa tranquilidad que no duraría mucho. A partir del último día de octubre el panorama empeoró seriamente, y según el padre Braña: «Aquí es donde verdaderamente empiezan los trabajos, calamidades, miserias; hasta ahora sólo ha sido un rasgo, una sombra de lo que se había de pasar y sufrir» (f. 9r). El 3 de noviembre, por la mañana, el cielo se oscureció en toda la laguna, sin duda por una tremenda nube eruptiva de ceniza. El volcán entró entonces en una actividad frenética, vomitando una lluvia de lava y bloques. La materia arrojada por el volcán produjo destrozos en Bayuyungán, Balayán, Ydang, Maragongdong, Liang, Calatang, Masug...:

Era cosa lastimosa ver cómo desamparaban estos miserables pobres indios sus pobres
casas, cómo trepaban por cuestas muy ásperas, enfermos, preñadas, niños de edad tan
tierna que no tenían aún seis años; estos angelitos a pie subían por la cuesta del
Sungay, que tiene dos horas y media de subida, y todo lo tenían a menos trabajo que
el perecer o entre las voraces llamas que vomitaba el volcán o entre las terribles olas
con que amenazaba la Laguna (f. 9v).

Esto último parece indicar que hubo un tsunami, que pudo haberse debido a una erupción submarina o por el contacto de los flujos piroclásticos 
con el agua del lago. Los piroclastos arrojados por el volcán fueron en tal cantidad que se anegó uno de los ríos más famosos de la provincia, el de Sampaloc. El Polo Grande prosiguió su furiosa actividad más o menos con la misma intensidad, y el 12 de noviembre el pueblo de Taal sufrió una pavorosa avalancha de agua y sedimentos que casi cubrió las casas, abriendo un río de unas cien brazas de ancho y veinte de profundidad. Esta oleada «se llevó hombres consigo, animales y casas; destruyó el mejor y más rico sitio que tenía aquel pueblo, que se llama Tubigán» (f. 10r). Taal padecería más avalanchas similares a la anterior, que incluso abrieron otro nuevo lecho, aunque bastante menor que el primero. ${ }^{27}$ Asimismo, se registraron oleadas de agua y aglomerado volcánico en lugares como Maputting Lupa y Bayuyungán.

Las dos crónicas que manejamos coinciden en señalar que durante los siguientes días persistió la violenta acción volcánica, con una lluvia de lodo que sepultó tierra fértil y anegó ríos. La madrugada del 25 de noviembre la situación empeoró más, a tal punto que hubo sismos en un radio de diez leguas, en medio de ingentes eyecciones de lava. Así lo relata vívidamente la Descripción Ajustada de México, al señalar que aquel día

\begin{abstract}
...empezó a oírse un bramido tan desacompasado y extraordinario que dejó atónitos a los del contorno, y del movimiento que se excitó dentro del volcán tembló la tierra por más de diez leguas en circuito terriblemente por espacio de medio cuarto de hora, y arrojando tanto fuego que no se veía otra cosa en mucha distancia. Creció el agua de la laguna tanto, que en el pueblo de Lipa se comió dos calles, y en los de Tanauán y Sala llegó hasta el patio de la iglesia; pero se volvió hacia la playa, sólo destruyendo el camino para el pueblo de Sala y dejando tan salobre el agua de los ríos que no se podía beber y no pudiéndose pescar por haber entrado la laguna en el bosque (11 r-v).
\end{abstract}

A partir del día 25 de noviembre se vivirían momentos muy duros en distintos puntos de la laguna, especialmente en torno al pueblo de Taal, donde durante nueve días el viento del este arrastró gases emanados del volcán, al tiempo que arrojaba todo tipo de tefra. El día 3 de diciembre sobrevino una oscuridad absoluta, como antes no se había conocido, que imposibilitaba deambular por las calles. Según Braña, hacia las tres de la tarde el volcán retomó una actividad furiosa: «Salió mucho fuego de toda la laguna, hubo

27 La crónica mexicana se hace eco de este hecho, afirmando que el material arrastrado por la avalancha llegó hasta lo alto de los tejados de las casas, abriendo «cauce a un río de cien brazas de ancho y veinte de hondo, llevándose esta avenida cuanto encontró: casas, animales y aun algunos hombres» (f. 10v). 
horribles temblores, terribles bramidos, espantosos truenos, así dentro del volcán como en las nubes que formaba el humo, con continuos relámpagos, culebrinas y centellas» (f. 11r). A continuación llovió lodo con tanta fuerza y constancia que derribó la mayoría de las casas en Tanauán, Sala y Lipa. Esta situación se prolongó durante los siguientes días, devastando nuevamente los campos. Como consecuencia de las efusiones volcánicas el agua quedó además contaminada lo que, sumado a la carencia de pasto, produjo la muerte tanto de ganado como de fauna salvaje.

Para estas fechas, de acuerdo con el padre Braña, el gobernador de Filipinas, Pedro Manuel de Arandía, había enviado ya algunos sampanes con provisiones y ayuda para los afectados. De las palabras del agustino parece desprenderse que incluso había llegado algún socorro del que por entonces era calificador del Santo Oficio, el dominico fray Juan Albarrán. El anónimo mexicano también se hace eco de las providencias adoptadas por el Gobierno de Manila para auxiliar a las víctimas, elogiando la acogida dispensada por los diferentes pueblos a los refugiados de la laguna de Taal. ${ }^{28}$

Entre tanto, el volcán prosiguió su acción destructora, y el día 12 de diciembre sobrevino una verdadera crisis: «Fueron tantos los bramidos de la mar y el volcán, tales las olas, tan grande el fuego que salió de la Laguna, que pensamos todos fuese el último término del volcán y se sorbiese la Laguna todos estos pueblos circunvecinos» (f. 11v). Aquel día por la tarde se asistió a uno de los sismos más potentes que se recordaban desde el 3 de noviembre, generándose una columna eruptiva tan densa que las consecuencias de la erupción sólo se pudieron conocer al día siguiente, apreciándose entonces que la tremenda sacudida había acabado con uno de los montes que se extendía al oeste del volcán. Con todo, aquello había sido el estertor final, la clarinada que ponía fin a tanto padecimiento. Tras aquel concierto de fuego y humo, entre estremecimientos telúricos, «cesó de repente la tempestad, y se serenó el tiempo, aclarándose del todo el día trece, desde el que no ha habido hasta ahora novedad alguna». ${ }^{29}$ Los últimos meses habían sido espantosos, pero todo había acabado ya, repentinamente, tras siete meses de pesadilla. Sin embargo, ahora tocaba enfrentarse a otra realidad igualmente cruel: ver el alcance de los destrozos, calcular las víctimas, socorrer a los damnificados y, en fin, iniciar la reconstrucción de aquella otrora floreciente región de Filipinas.

28 Descripción Ajustada..., 12v.

29 Idem. 


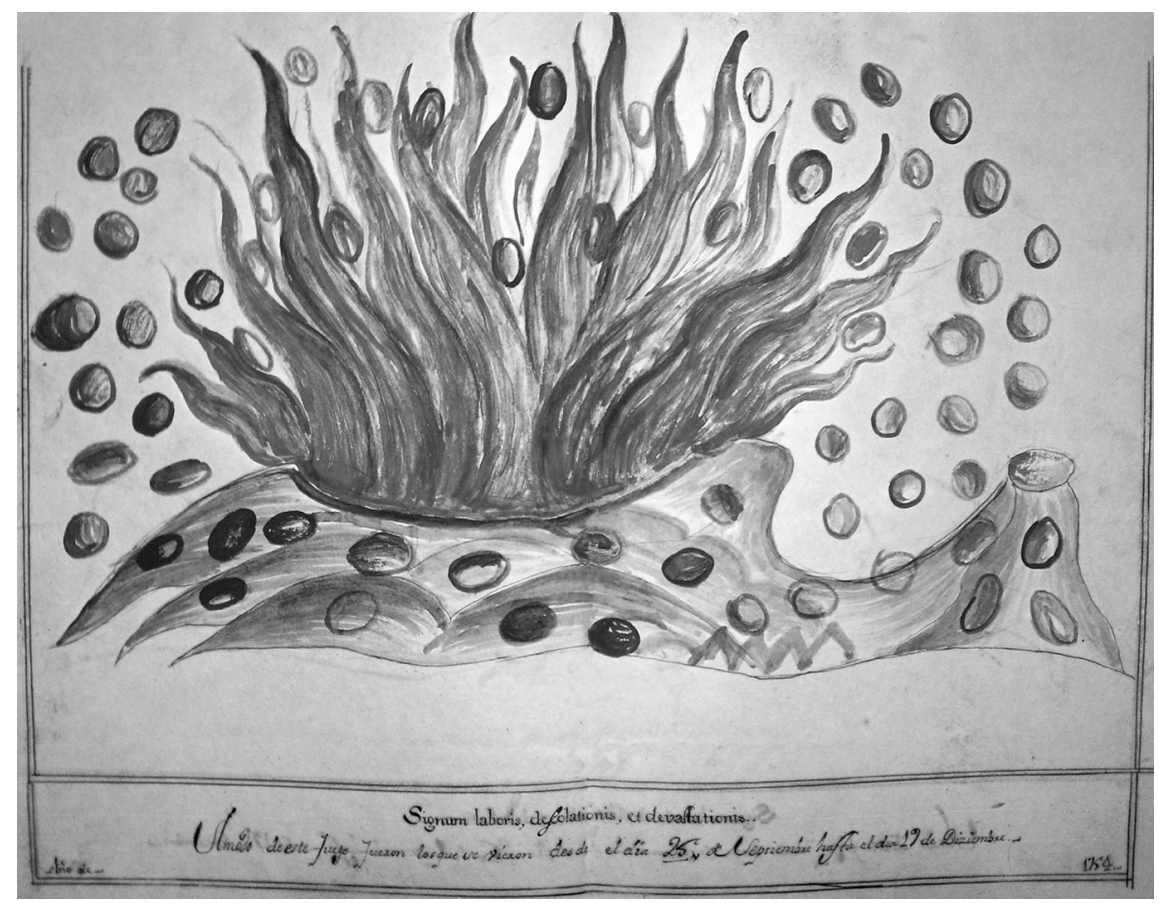

Figura 4. Representación de la actividad del volcán de Taal por fray Miguel Braña, contenida en su Relación sobre los sucesos de 1754 (Archivo Franciscano Ibero-Oriental). Al pie de la acuarela se puede leer: «A modo de este fuego fueron los que se vieron desde el día 25 de septiembre hasta el día 19 de diciembre.» Quizá se trate de un error de forma, ya que el propio autor señala en su manuscrito que la actividad volcánica se extendió hasta el 12 de diciembre, cesando al día siguiente.

\section{Quare perierit terra et exusta sit quasi desertam: La región de Taal, entre la agonía y la reconstrucción}

La erupción explosiva del volcán de Taal en 1754 fue tremendamente destructiva, conociendo episodios de verdadera virulencia. Algunos la han calificado como una erupción freatomagmática violenta, aunque otros la consideran del tipo pliniano. ${ }^{30}$ En cualquier caso, constituyó un fenómeno

30 Hargrove, 1991, 146, la estima del primer tipo, mientras que el PHIVOLCS juzga que es del segundo. 
demoledor: lava, rocas, cenizas, emanaciones gaseosas y, con toda seguridad, lluvia ácida; avalanchas de lodo; tsunamis... La tierra quedó abrasada y el agua del lago y de los ríos contaminada. Inundaciones, desprendimientos, fracturas de tierra y terremotos acabaron con la vida de numerosas personas. ${ }^{31}$ La crónica anónima de México describe así la situación:

El daño de esta provincia es incomparable, porque con la multitud de piedra y copia grandísima de arena se han vuelto estériles los campos, se han perdido los árboles, ha faltado todo el ganado de carabaos, vacas y caballos, con todo el venado y caza de los montes, y asolados los pueblos se han esparcido los habitadores por varios sitios, en donde la falta de todo y la malignidad de las aguas con la mutación tan sensible del temple los ha ido consumiendo con mortandad considerable..$^{32}$

El estado tan calamitoso en que quedó sumida la región propició la aparición de otros males, siendo el primero el espectro de las epidemias y las enfermedades. ${ }^{33}$ Por otra parte, debido a la situación de desprotección y desconcierto que reinaba en la provincia, los piratas malayo-musulmanes aprovecharon para efectuar algunos golpes de mano, quemando Batangas y Balayán, con las consiguientes secuelas de destrucción, muerte y cautiverio. ${ }^{34}$ Aunque el enemigo también podía encontrarse dentro, ya que esa misma falta de seguridad, unida a una situación de pobreza y desarraigo, favoreció un espectacular aumento de la criminalidad, como denuncia fray Miguel Braña,

...que no hay pasajero seguro en los Caminos reales, no hay hacienda, no hay honra, no hay vida libre de sus manos. Siempre ha habido ladrones, al menos de muchos años a esta parte, pero con la insolencia y atrevimiento que ahora, jamás lo han

31 Sobre las consecuencias de una erupción volcánica en el medio ambiente véase Lebon, 2009, 29-43, donde se estudian los casos recientes de los volcanes filipinos de Pinatubo y Mayón. Acerca del impacto volcánico en las sociedades agrícolas de la América hispana, Petit-Breuilh, 2004b. Entre otros, analiza las consecuencias de la erupción del Huainaputina en 1600 en la comarca de Arequipa, pudiendo establecerse analogías con lo acaecido en Taal en 1754: erupción explosiva, continua caída de ceniza y lapili, con flujos piroclásticos que sepultaron pueblos de indios; pobreza, hambre y enfermedades posteriores entre la población... Cabe decir que así como tras la erupción de 1749 en Taal, el volcán siguió dando señales de actividad a menor nivel, hasta llegar a la catástrofe de 1754, en el caso arequipeño hubo reactivaciones intermitentes durante unos tres años, aunque no se terminó desencadenando otra segunda erupción.

32 Descripción ajustada..., 12v.

33 AGI, Filipinas, 162, n. 3, Certificazion de Officiales Reales sobre los Tributos que la Provincia de Balayan tenia antes de las Irrupciones del Bolcan y Moros el en que quedó [sic] después de dicha irrupción y el que al presente tiene por la nueva numeración de tributos. Año de 1758, 1. ${ }^{a}$ Vía. Está inserta en la carta que envía el gobernador Arandía a Julián de Arriaga, Manila, 15 de julio de 1758.

34 Descripción ajustada..., 12v; AGI, Filipinas, 335, L. 17, 181r-183v. 
experimentado los nacidos. Es de suerte que, en parecer de todos los naturales, son mayores los daños que causan estos que los que ha hecho la langosta y el volcán. En estos tres años pasados, pasan de dos mil los bueyes de arado que han hurtado, fuera carabaos y caballos. Decir las muertes alevosas, heridas traidoras que por aquí ha habido no es posible. ${ }^{35}$

Para colmo, incluso uno de los navíos enviados por el Superior Gobierno de Manila con ropa y alimentos para socorrer a los damnificados se fue a pique en la bahía de Balayán. ${ }^{36}$ ¿Pero cuál fue el coste humano y material de la tragedia? El volcán destruyó las poblaciones de la laguna de Taal y algunas otras de la provincia de Balayán, haciendo sentir su furia incluso en diversos puntos de Laguna de Bay, pero la documentación no proporciona datos fehacientes que permitan evaluar realmente el alcance de la pérdida material. Apenas sabemos, según un informe elaborado en 1757 por los oficiales reales de Hacienda, que los daños provocados por el volcán en la provincia de Balayán hicieron disminuir los ingresos fiscales en 9.446 pesos. ${ }^{37}$

En cuanto a la pérdida de vidas humanas, los documentos de la Administración sugieren una idea aproximada. Una de las primeras medidas adoptadas por el gobernador Arandía fue conocer el número de habitantes que restaban en Balayán tras las muertes y el éxodo poblacional provocado por el volcán. Paralelamente, inició una política de reconstrucción y recuperación económica de la región, que poco a poco atrajo de vuelta a sus lugares de origen a los huidos. De esta manera, en 1758 el gobernador ordenó un nuevo censo de la población, comparándolo con los cómputos obtenidos en los años anteriores. ${ }^{38}$ Se pudo comprobar que en 1753 la provincia tenía 25.881 habitantes «de todos los sexos y edades», resultando 5.834 tributos. Tras el azote del volcán y sus secuelas, se experimentó una drástica disminución: 12.814 almas, con apenas 2.814 tributos. Las medidas destinadas a la recuperación de la provincia introdujeron una mejoría,

35 Relación de lo sucedido..., $15 \mathrm{v}$.

36 Hargrove, 1991, 32.

37 AGI, Filipinas, 160, n. 20, Testimonio de la zertificación dada por Ofiziales Reales de la baja, y aumento de las Rentas Reales de S. M. en estas Cajas, expecialmente por lo que haze al producto de Reales Tributos, en vista de lo que han padecido las Provincias por las Inbasiones de Moros, e Irrupciones del Bolcan con liquidación de menos fondo que ha tenido la Caxa en el presente Govierno. Año 1757, 1. ${ }^{a}$ Vía. Está inserto en una carta de Arandía a Arriaga, Manila, 24 de julio de 1757.

38 AGI, Filipinas, 162, n. 3, Testimonio relativo de la disminucion de havitantes de la Provincia de Balaian causada de las Irrupciones del Bolcan e imbaciones de moros y su restablecimiento en virtud de repetidas Providencias del Superior Govierno. Año de 1758, 1. ${ }^{\mathrm{a}}$ Vía. Inserto en la carta de Arandía a Arriaga, Manila, 15 de julio de 1758. 
de forma que a fecha de 26 de abril de 1758 Balayán contaba con 23.521 habitantes, recaudándose ya 5.186 tributos ${ }^{39}$ habiendo regresado a sus pueblos 10.707 personas..$^{40}$ Balayán había perdido a causa de la catástrofe, entre muertos y huidos, 13.067 personas, un 50'48 \% de su población. Con la política de reconstrucción promovida por el Gobierno de Manila y el regreso de los refugiados, en 1758 se alcanzó esa cifra de 23.521 habitantes, lo que constituía el 90,88 \% de la población censada en 1753. Faltaban, no obstante, 2.360 personas, más del $9 \%$ de los habitantes recogidos aquel año. ¿Es esa realmente la cifra de víctimas ocasionadas por la catástrofe volcánica? Es arriesgado afirmarlo sin hacer antes algunas consideraciones.

Hemos de tener en cuenta que no todos los supervivientes que abandonaron la laguna tuvieron por qué retornar. Es posible que algunos encontraran mejores condiciones de vida en las provincias donde se refugiaron, y quizá hubiera también quien aprovechase la ocasión para escapar a la presión fiscal y resolviera remontarse, es decir, instalarse en zonas apartadas y agrestes para eludir el control administrativo. ${ }^{41}$ En otro sentido, está el hecho de que el censo de 1758 reúne a toda la población, sin hacer discriminación por edad, incluyendo a los nacidos después de 1754: unas vidas nuevas que están reemplazando a aquellos que, censados antes de la catástrofe, murieron durante la erupción o fallecieron después lejos de Taal a consecuencia de las lesiones provocadas por aquélla, siendo de igual modo víctimas del volcán. Por otro lado, las secuelas de la erupción volcánica también causaron bajas mortales entre aquellos que, precisamente, no habían huido. Así pues, creemos que esta cifra de 2.360 personas de menos que se registró en el cómputo poblacional de 1758 no puede considerarse como la cantidad neta de víctimas producidas exclusivamente por la acción volcánica de 1754, aunque constituye un indicador que ayuda a ponderar el número de muertos que ocasionó el vulcanismo, sumado a sus efectos posteriores, tanto físicos (hambre, envenenamiento, enfermedades) como sociales (ataques piratas y bandolerismo).

39 Según el informe elaborado, fueron excluidos 1.036 tributos y medio que tenían en ese momento los pueblos de Tiaong y San Pablo, que habían sido agregados a la provincia de Balayán, pero que cuando se produjo la erupción del volcán pertenecían a las provincias de Laguna de Bay y Tayabas. (Cf. AGI, Filipinas, 162, n. 3, Certificación de Officiales Reales sobre Tributos..., 1758).

40 El documento indica 10.759, lo que debe ser un error de copia o de cómputo.

41 Aunque no siempre era fácil escapar a la vigilancia de la Administración en las provincias cercanas a Manila. La propia movilidad de una provincia a otra también tenía sus trabas, pues obligaba a unos requisitos administrativos de cara a mantener el control fiscal. Había un apremio de la Administración española para mantener a las poblaciones estables y lo menos dispersas posibles. 
NUEVAS FUENTES PARA EL ESTUDIO DE LA ERUPCIÓN DEL VOLCÁN DE TAAL

FIGURA 7

OSCILACIÓN DE LA POBLACIÓN EN BALAYÁN ENTRE 1753 Y 1758

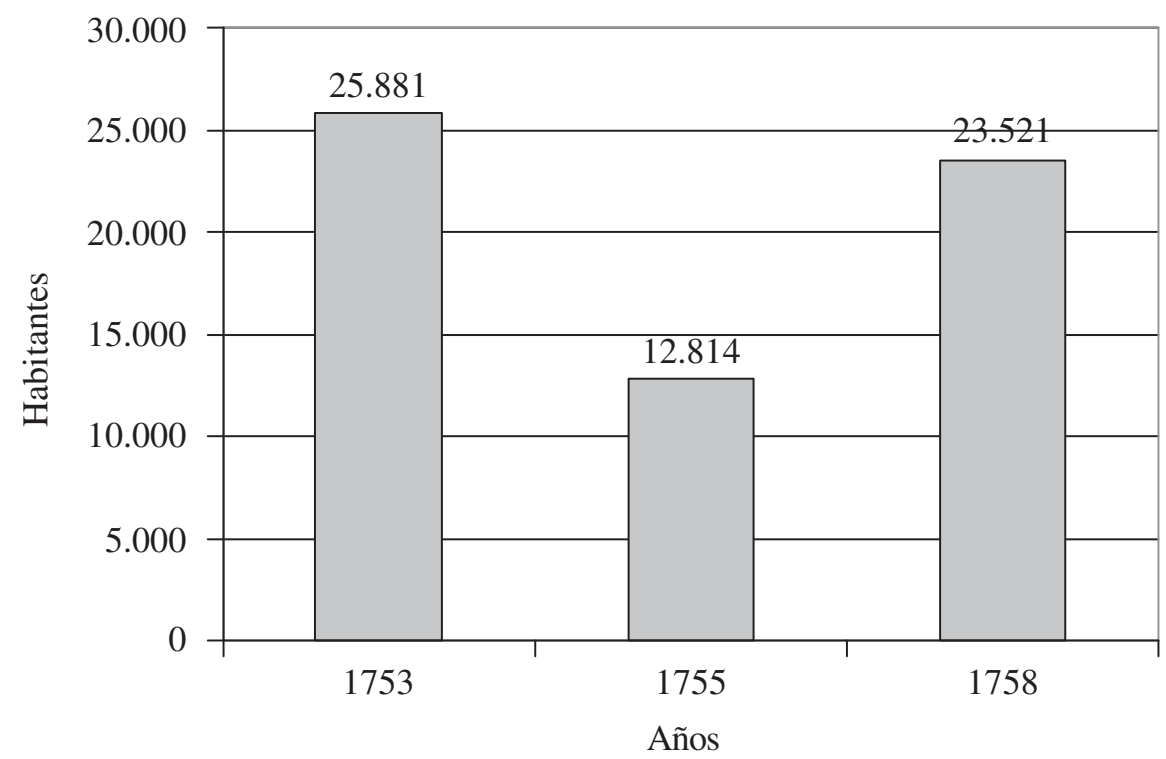

La primera medida que adoptó el Gobierno de Manila para paliar las consecuencias de la catástrofe consistió en el envío de navíos con víveres, para socorrer a las víctimas y evitar un despoblamiento aún mayor de la región. ${ }^{42}$ La ayuda remitida desde Manila ascendió a 7.741 cavanes y 23 gantas de arroz, que importaron, junto con el flete para su transporte, 7.260 pesos. Pero la habitualmente empeñada Hacienda filipina no podía deshacerse de esa cantidad tan fácilmente, por lo que el auxilio constituyó más bien un préstamo, dado que la suma habrían luego de reintegrarla «en prorrata dichos naturales, según la percepción de cada uno». ${ }^{43}$ Otra de las providencias gubernamentales tuvo en cuenta la ubicación de las poblaciones. Los terrenos alrededor de la laguna de Taal habían quedado contaminados ${ }^{44}$ mientras que los ríos sufrieron alteraciones en sus cursos o se

42 AGI, Filipinas, 386, n. 21, Carta de Arriaga a Arandía, Madrid, 2 de septiembre de 1756.

43 AGI, Filipinas, 162, n. 3, Carta de Arandía a Arriaga, Manila, 15 de julio de 1758. Certificazion de Officiales Reales sobre los Tributos...

44 Ibidem, Carta de Arandía a Arriaga, Manila, 15 de julio de 1758. 
vieron anegados. Se hizo imposible la agricultura, lo que provocó el éxodo de los nativos. Taal había sido una zona tradicionalmente bastante productiva, y precisamente el informe redactado en 1758 hacía hincapié en que la región debía recuperar su potencial agrícola y reanudar la manufactura del algodón. ${ }^{45}$ En vista de todo ello, el gobernador de Filipinas inició su tarea de reconstrucción y recuperación económica teniendo en cuenta que, para alcanzar este objetivo, debía cambiar el emplazamiento de algunos pueblos a lugares más propicios, tarea que requería una buena dosis de diplomacia con los naturales a la hora de establecer los términos de cada lugar, por tratarse de un «obstáculo entre ellos de la mayor delicadez».46

Cuatro poblaciones mudaron su ubicación junto a la laguna: Lipa, Tanauán, Taal y Sala, cuyos moradores fueron trasladados por orden del Gobierno de Manila a otros puntos más seguros ${ }^{47}$ Tanauán se movió primero hacia el este, adonde se encontraba Sala (cerca de la actual Bañadero), y un año después ambos vecindarios se mudaron juntos aún más al este, edificándose una nueva ciudad a unos 10 kilómetros hacia el noreste del margen de la laguna y a unos 170 metros sobre el nivel de sus aguas, en un emplazamiento más resguardado de futuras eventualidades volcánicas. ${ }^{48}$ El lugar siguió llamándose Tanauán, convirtiéndose Sala en un barrio del mismo. Lipa también se alejó de la orilla del lago, desplazándose hacia el sureste. Taal abandonó el sitio que ocupaba desde 1572 y se trasladó hacia el sur, hacia la bahía de Balayán. ${ }^{49}$

El mapa de la figura 6 fue elaborado por fray Miguel Braña, incluyéndolo en su manuscrito como una demostración del estado de la región de la laguna de Taal tras la acción volcánica: «Así ha quedado la Provincia y los montes de la Laguna destruidos y abrasados», se lee en el boceto. No obstante, el dibujo no refleja todavía los cambios introducidos por el Gobierno de Manila, ya que las poblaciones siguen situadas en los asentamientos que ocupaban en 1754. Con todo, muestra un detalle interesante. En la parte

45 Ibidem, Certificazion de Officales Reales sobre los Tributos...

46 Ibidem, Carta de Arandía a Arriaga, Manila, 15 de julio de 1758.

47 Hargrove, 1991, 33. En la página 19 hay un mapa que ilustra estos cambios. El autor trata de manera detallada este asunto y la búsqueda de los emplazamientos antiguos en los capítulos 4,5 y 6 de su obra.

48 Centeno, 1885, 2.

49 En la América española era frecuente que una población que mudaba su emplazamiento a raíz de un desastre cambiara también su nombre para romper lazos con la ciudad antigua (Musset, 1996). En el caso que estudiamos, sin embargo, no se produjo nada de esto, manteniéndose las antiguas denominaciones. 


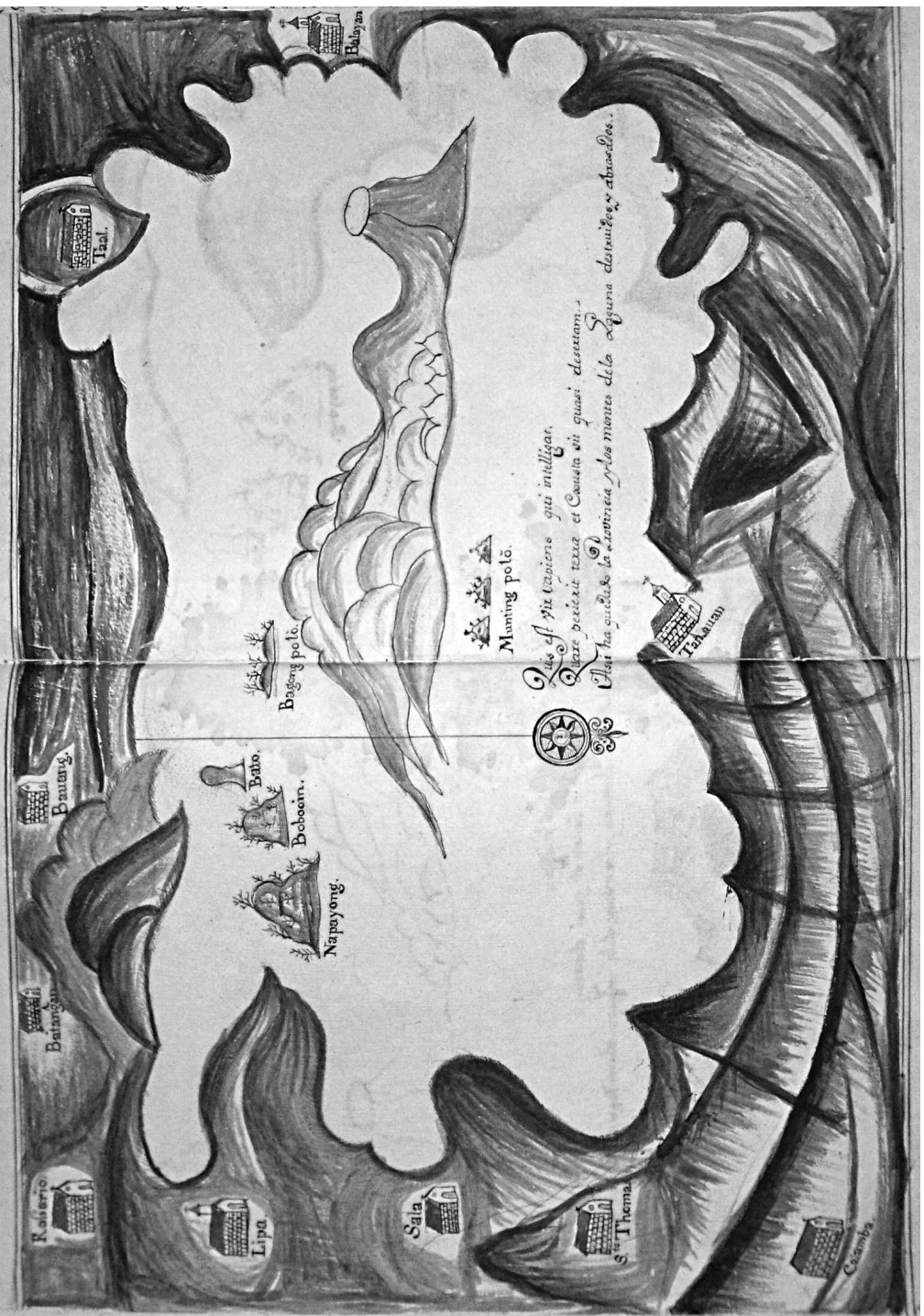

密 $\frac{\text { c }}{0}$

寻

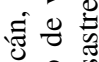

용

$\bar{\nabla} \cdot \frac{0}{0}$

:

를 छ릴

๘ $\overline{0}$

‡

\pm 类

丞

记的哥

菏

흐 플

․․ है

$\underset{0}{0} 0^{\circ}$

동

$\stackrel{0}{0}$

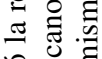

过 $\frac{0}{0}$

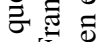

空

히월

원

萦艺

흉

芯 $\stackrel{0}{0}_{0}^{2}$

$\sum .0$

$\cdot \dot{2}$

접

$\Xi_{0}=$ 
superior izquierda (equivalente al sur) se encuentra enclavada Taal en su emplazamiento primitivo. Ya hemos señalado que existía un canal que hacía desaguar la laguna en el mar. Braña ha dibujado alrededor de Taal dos cauces, quizá queriendo indicar de esta manera tanto el que ya existía como aquel otro de gran tamaño originado a raíz de las avalanchas de lodo y rocas que sufrió la localidad a finales de noviembre de 1754. Los límites del mapa no permiten saber si dichos cauces se prolongarían o no hasta la bahía de Balayán. Pero llama la atención que el fraile haya tapado con sendos trazos las bocas de estos lechos cuando se juntan con el lago. ¿Quiso indicar así que estaban ya anegados, habiendo quedado obstruida la comunicación con el mar?

\section{El particular viacrucis de Balayán}

Vamos a concluir este apartado analizando algunos aspectos de la lenta y penosa recuperación de una de las localidades afectadas, Balayán, de la que poseemos información digna de interés. Antes de que reventara el volcán de Taal, Balayán había sido un pueblo de 1.500 tributos, agrícolamente muy rico, con diversas visitas o barrios. Pero toda aquella bonanza terminó el fatídico año de 1754, fruto de la acción volcánica, de la peste y de las hambrunas. Además, padeció los ataques de los piratas malayomahometanos,

muriendo muchos indios a manos de los moros, llorando infinitos su triste cautiverio, separado de los infinitos que habían perecido (en la peste padecida) en los campos a donde huyeron acosados del hambre, para comer raíces y hierbas no conocidas, a fin de conservar la vida. ${ }^{50}$

En 1760 el arzobispo de Manila, Manuel Antonio Rojo, realizó una visita a Balayán, momento que aprovechó una representación del municipio para hacerle entrega de un memorial solicitando su intercesión. Los vecinos afirmaban no tener de dónde extraer su sustento y mucho menos fondos para pagar los tributos. La localidad aún padecía un gran éxodo poblacional a causa del estado en el que había quedado sumida, a pesar de que algunos emigrados habían regresado al pueblo, integrándose en las

50 AGI, Filipinas, 335, libro 17, 181r-183v, Real Cédula al gobernador de Filipinas, San Lorenzo, 23 de octubre de 1761. 
tareas de reconstrucción. ${ }^{51}$ Rogaban que el arzobispo intercediera ante el rey para que les eximiera del pago de los tributos durante algunos años, comprometiéndose por su parte a reconstruir la iglesia y el fuerte locales. Las quejas de los moradores de Balayán se vieron reforzadas por otro informe redactado por Ramón de Orendaín, alcalde mayor de la provincia. Orendaín ratificó el lamentable estado en el que se encontraba la población y lo mucho que se había trabajado en la erección de una nueva fortaleza, señalando que a pesar de haberse elevado diversas súplicas al Gobierno de Manila solicitando la exención fiscal temporal, ésta había sido sistemáticamente negada, «concediéndoles sólo la gracia por un año de los polos».

Aunque deben analizarse con cautela los documentos que reflejan quejas sobre desgracias y agravios, debido a la natural inclinación humana a exagerar los males propios, no parece que careciera de razón el vecindario de Balayán, pues los daños ocasionados por el volcán todavía eran recientes, mientras que la delincuencia y los ataques piratas constituían un azote que iba a persistir durante bastantes años. En una fecha tan avanzada como 1790, un religioso agustino que recorrió durante varios meses la provincia — que tras la erupción de 1754 pasó a denominarse Batangas-, ${ }^{52}$ señalaba que las dos grandes calamidades que asolaban la región eran, en primer lugar, el bandolerismo y la criminalidad, seguido de los asaltos de los piratas moros del sur, con su secuela de destrucción y cautiverio. Según este viajero, para entonces Balayán llevaba padecidos ya tres saqueos de las bandas malayo-musulmanas..$^{53}$

El 17 de junio de 1760, tras su regreso a Manila, el arzobispo remitió una carta al rey de España, transmitiendo al monarca las quejas y las súplicas que había recibido. La misiva alcanzó su objetivo, y una cédula de octubre de 1761 eximió a los habitantes de Balayán durante cuatro años del pago de tributos y del trabajo en los polos, para que se dedicasen a las labores de reconstrucción del pueblo. Además, una orden destinada al gobernador

51 Idem. La Real Cédula elogia la actitud del alcalde mayor, quien favoreció la nueva fundación y el arraigo de los pobladores, proporcionándoles todo tipo de materiales y alimento.

52 Archivo Histórico Nacional (AHN), Códices y Cartularios, libro 1270, Historia de la Provincia de Batangas escrita por don Pedro Andrés de Castro y Amadeo en sus viajes y contra viajes en toda esta Provincia, año de 1790 (copia), 176r-253v. El nombre del religioso era en realidad fray Agustín María de Castro (Pérez, 1901, 314-317).

53 Para ponderar la grave situación que atravesó la provincia pensemos que, de acuerdo con los datos que proporciona Castro, el pueblo de Batangas, que fue el menos afectado por la erupción volcánica, sufrió entre 1757 y 1763 dos epidemias, una inundación del río, un saqueo por parte de los piratas moros y otro más en 1763, perpetrado por las tropas británicas, que el año anterior habían ocupado Manila. 
dispuso que si lo anterior no fuera suficiente, el Gobierno de Manila debería socorrer a los vecinos de Balayán. ${ }^{54}$ El gobernador, entonces José Antonio Raón, siguió de cerca la situación de la localidad, pudiendo informar a la Corte en 1766 que, desde 1757, se observaba una recuperación poblacional a raíz del envío a cuenta de la Hacienda pública de alimentos y armas, habiendo regresado unos 300 tributarios.

En su carta al rey de 1760, el arzobispo Rojo refería que Balayán contaba con 360 vecinos, mientras que en 1766 Raón señalaba que había ya más de 600. El incremento de población era sin duda un signo de recuperación material. No obstante, el gobernador participó al rey la aprensión de los naturales, que seguían sin concluir las tareas de reconstrucción debido al nivel de indigencia en que aún se encontraban y a la necesidad de defender la tierra de los incesantes ataques de los piratas. Se mostraban además preocupados porque aquel año expiraba la exención de polos y tributos de la que habían gozado. En vista de ello, el soberano prorrogó la exención dos años más, ordenando al gobernador que suministrase más munición a los vecinos para la defensa del pueblo, hasta que éstos se encontrasen en condiciones de poder comprarla. ${ }^{55}$

\section{Conclusiones}

La acción volcánica acaecida en la laguna de Taal en 1754 constituyó un hecho sin precedentes. Desde 1749, año en que el volcán entró en acción de manera virulenta aunque breve, fueron frecuentes ligeras reactivaciones eruptivas. Sin embargo, la vulcanología no estaba desarrollada y nadie imaginó lo que habría de venir pocos años más tarde: una actividad de siete meses que dejó la región en torno a la laguna devastada, haciendo necesaria una ingente tarea de reconstrucción posterior.

Como consecuencia de las víctimas mortales y del éxodo humano que se produjo hacia las comarcas limítrofes, la provincia de Balayán perdió más de la mitad de su población. La política seguida por el Gobierno de Manila permitió su recuperación en los años inmediatos. Con todo, la cifra de habitantes que arrojó el censo confeccionado en 1758 era inferior en

54 AGI, Filipinas, 336, libro 18, 5r-7v, Real Cédula al gobernador de Filipinas, El Pardo 13 de febrero de 1768 .

55 Idem. 
más de un nueve por ciento al número de pobladores existente en 1753. Aunque quizá todavía restasen personas por regresar a su provincia de origen, la cantidad puede ser indicativa del número de víctimas provocadas por la acción del volcán y sus secuelas de enfermedades, hambre, criminalidad e incluso incursiones de saqueo de los piratas malayo-musulmanes en un terreno que quedó indefenso.

Las fuentes presentadas para la narración de los acontecimientos son en parte inéditas. La crónica que se conserva en el Archivo de la Nación de México, calificada como anónima hasta la fecha, si se contrasta con la que se guarda en el Archivo Franciscano Ibero-Oriental, presenta un parecido que va más allá de la mera casualidad. Consideramos que ambas son obra de un mismo autor, el agustino fray Miguel Braña, párroco de Tanauán en 1754 y testigo de la tragedia, quien las compuso en momentos distintos, añadiendo incluso ilustraciones, sin duda con intención de dar una mayor divulgación y dejar una mejor constancia de los tremendos acontecimientos que había presenciado, capaces, tanto entonces como ahora, de dejar asombrado por su colosal magnitud a cualquier ser humano.

Recibido el 27 de febrero de 2014 Aceptado el 22 de septiembre de 2014

\section{Bibliografía}

Alberola Romá, Armando: Desastre natural, vida cotidiana y religiosidad popular en la España moderna y contemporánea, San Vicente del Raspeig, Universitat d'Alacant, 2009.

Alberola Romá, Armando: Clima, naturaleza y desastre: España e Hispanoamérica durante la Edad Moderna, Valencia, Universitat de València, 2013.

Antón Burgos, Francisco Javier: «El medio físico de las islas Filipinas», en Cabrero, Leoncio (coord.), Historia General de Filipinas, Madrid, Ediciones de Cultura Hispánica/Agencia Española de Cooperación Internacional, 2000, $17-46$.

Aragonés, Fray Juan J.: Catálogo de los religiosos de N. P. S. Agustín de la Provincia del Smo. Nombre de Jesús de Filipinas, Manila, Ramírez y Giraudier, 1864.

Araña Saavedra, Vicente y Ortiz Ramis, Ramón: Volcanología, Madrid, Consejo Superior de Investigaciones Científicas/Editorial Rueda, 1984.

Asian Disaster Preparedness Centre: The Philippines Disaster Management Story: Issues and Challenges, Pathumthani, Tailandia, octubre de 2001. 
Centeno, José: Estudio geológico del volcán de Taal, Madrid, Imprenta y Fundición de Manuel Tello, 1885.

Donoso Jiménez, Isaac: "Vulcanismo y cultura filipina en el siglo XVIII», Cuadernos Dieciochistas, 7, Salamanca, Ed. Universidad de Salamanca, 2006, 141-167.

Hargrove, Thomas R.: The Mysteries of Taal. A Philippine volcano and lake, Manila, Bookmark Publishing, 1991.

Lebon, Sylviane L. G.: Volcanic activity and evironment: Impacts on agriculture and use of geological data to improve recovery processes, Nordic Volcanological Centre, Institute of Earth Sciences, University of Iceland, report 0901, 2009.

Mas y Otzet, Francisco de: El Volcán de Taal. Poema, Madrid, F. Bueno y Compañía Editores, 1885.

Murillo Velarde, Pedro: Geographia historica de las Islas Philipinas, del Africa, y de sus islas adyacentes, Madrid, Oficina de Gabriel Ramírez, 1752, tomo VIII.

Musset, Alain: «Mudarse o desaparecer. Traslado de ciudades en Hispanoamérica y desastres (siglos XVI-XVIII)», en García Acosta, Virginia (coord.), Historia y desastres en América Latina, vol. I, Bogotá, La Red/CIESAS, 1996, 41-69.

Parker, Geoffrey: El siglo maldito. Clima, guerra y catástrofes en el siglo XVII, Barcelona, Editorial Planeta, 2013.

Pérez, Fray Elviro J.: Catálogo bio-bibliográfico de los agustinos de la Provincia del Santísimo nombre de Jesús de las Islas Filipinas, desde su fundación hasta nuestros días, Manila, Tipología del Colegio de Santo Tomás, 1901.

Petit-Breuilh Sepúlveda, María Eugenia: «Conjuros y exorcismos ante los desastres naturales en Hispanoamérica (siglos XVI-XVIII)», en González Ruiz, David (ed.), Ritos y ceremonias en el mundo hispano durante la Edad Moderna, Actas del II Encuentro Iberoamericano de religiosidad y costumbres populares, Huelva, Universidad de Huelva/Centro de Estudios Rocieros, 2002, 331-351.

Petit-Breuilh Sepúlveda, María Eugenia: La historia eruptiva de los volcanes hispanoamericanos, siglos XVI al XX: el modelo chileno, Lanzarote, Servicio de Publicaciones del Cabildo Insular de Lanzarote, 2004a.

Petit-Breuilh Sepúlveda, María Eugenia: «Efectos de los desastres naturales en la economía rural de Hispanoamérica durante el siglo XVII», en Aranda Pérez, Francisco José (coord.), El mundo rural en la España moderna. Actas de la VII Reunión Científica de la Fundación Española de Historia Moderna, vol. 2, Cuenca, Ediciones de la Universidad de Castilla-La Mancha, 2004b, 515-528.

Petit-Breuilh Sepúlveda, María Eugenia: Naturaleza y desastres en Hispanoamérica. La visión de los indígenas, Madrid, Sílex, 2006. 